University of Nebraska - Lincoln

DigitalCommons@University of Nebraska - Lincoln

Publications, Agencies and Staff of the U.S.

Department of Commerce

U.S. Department of Commerce

2011

From Observations to Forecasts - Part 8: The use of satellite observations in numerical weather prediction

\author{
Andrew Collard \\ NOAA/NCEP/EMC \\ Fiona Hilton \\ Met Office \\ Mary Forsythe \\ Met Office \\ Brett Candy \\ Met Office
}

Follow this and additional works at: https://digitalcommons.unl.edu/usdeptcommercepub

Part of the Environmental Sciences Commons

Collard, Andrew; Hilton, Fiona; Forsythe, Mary; and Candy, Brett, "From Observations to Forecasts - Part 8: The use of satellite observations in numerical weather prediction" (2011). Publications, Agencies and Staff of the U.S. Department of Commerce. 253.

https://digitalcommons.unl.edu/usdeptcommercepub/253

This Article is brought to you for free and open access by the U.S. Department of Commerce at DigitalCommons@University of Nebraska - Lincoln. It has been accepted for inclusion in Publications, Agencies and Staff of the U.S. Department of Commerce by an authorized administrator of DigitalCommons@University of Nebraska - Lincoln. 


\section{From Observations to Forecasts - Part 8: The use of satellite observations in numerical weather prediction}

\author{
Andrew Collard, ${ }^{1}$ Fiona \\ Hilton, ${ }^{2+}$ Mary Forsythe ${ }^{2 \dagger}$ \\ and Brett Candy ${ }^{2+}$ \\ 'IMSG at NOAA/NCEP/EMC, Camp \\ Springs, Maryland, USA \\ ${ }^{2}$ Met Office, Exeter
}

\section{Introduction}

The use of satellites in weather prediction was introduced in an earlier article in this series (Kidd, 2010) which focused on satellite imagery, used primarily by forecasters and researchers to observe and understand synoptic scale weather patterns and their development. Many types of satellite observation are also used directly in numerical weather prediction (NWP) models. Observations from up to 50 individual satellite instruments are routinely assimilated at many centres. This article reviews the main types of satellite observations used in NWP, how they are used and why they are important.

As is often the case in this field, this article contains a large number of abbreviations and acronyms. Rather than expand these in the text, we have included a list at the end of the article.

\section{Observations for NWP}

NWP models produce a 3-dimensional forecast of the future state of the atmosphere (temperature, humidity, winds, clouds and precipitation) from an estimate of the current state. The accuracy of forecasts produced by NWP models relies crucially on how well the initial state of the atmosphere can be described. This initial state, which is known as the analysis, is created by optimally combining observational data with a short-range forecast from the previous analysis through a process known as data assimilation (Daley, 1991; Rodgers, 2000; Kalnay, 2003; ECMWF, 2010). To produce an accurate analysis and consequently a good forecast requires good coverage of high-quality observations.

Weather observations are broadly divided into conventional observations (mostly from surface stations, aircraft and weather balloons), and those from satellites. Conventional instruments make very localised measurements and the observations have a patchy distribution around the globe, being most dense in Europe, North America and East Asia. Using satellites, we have the advantage that we can observe much of the globe within a short period: either nearly a hemisphere (from geostationary orbit) or the whole globe twice per day (from polar orbit). Figure 1 compares the distribution of radiosonde and aircraft observations in a six-hour forecast cycle with soundings from the ATOVS instruments, and satellite-derived atmospheric motion vectors. The excellent coverage of satellite data is part of the reason why they have become such an important part of the NWP global observing system over the last 30 years.

Most conventional instruments make direct, in situ, measurements of atmospheric variables which form part of the description of the model state, for example temperature, water vapour or wind. One complication with satellite data is that the instruments do not measure these atmospheric parameters directly. In general they observe electromagnetic radiation, which is either sent out by the satellite and reflected or scattered by the surface or clouds, or is emitted by the atmosphere and surface. The radiation measurement is therefore a complicated function of the temperature and composition of the entire depth of the atmosphere seen by the satellite.

Since satellite instruments do not measure the atmospheric components used in the NWP model directly, the assimilation of satellite data can be complex. One of two approaches is commonly used. Either synthetic observations are calculated from model data and then compared with the real observations so that the model state can be adjusted towards the observation (the preferred approach for sounding data), or the satellite observations are processed, usually with the help of model information, to retrieve the temperature, humidity or wind, which is then assimilated directly.

Satellite observations may be categorised in a number of ways:
Satellite orbit: Geostationary satellites are positioned over the Equator at a height of $35786 \mathrm{~km}$, orbiting at the same speed as the Earth rotates, and thus always view the same area of the planet. Each satellite can see about a quarter of the planet $\left(70^{\circ}\right.$ north, south, east and west of the sub-satellite point). Sun-synchronous orbits have an inclination of around $98^{\circ}$ with respect to the Equator (the exact value depends on the orbit height), such that they pass over the Equator at the same local time every orbit. Sun-synchronous satellites are in what is known as 'low-earth orbit', as they are much closer to the earth (around 600-850km). This allows more detailed measurements of the atmosphere. These satellites are often referred to as 'polar-orbiters'.

Viewing geometry: Satellite observations are either made in the nadir direction (which may be up to $70^{\circ}$ from viewing straight down but which has a line of sight that intersects the surface) or in the limb direction (where the background is space). Limb sounders are not generally used to observe the troposphere, as in most instances that would require unfeasible pointing accuracy and field-of-view. They do not have a large influence on global numerical weather prediction, the exception being GPS radio-occultation (GPSRO) measurements.

Active and passive: Satellite instruments either measure the radiation emitted naturally by the atmosphere (passive observations), or are radar or LiDAR systems that emit radiation and observe the reflection. Apart from scatterometers, which are used to infer surface winds from wind-induced surface ripples, and the GPSRO system, which measures the effect of the atmosphere on the signals from the GPS constellation, most instruments used in NWP at present are passive.

Geophysical variables: Satellite observations may also be divided into those that provide information on the global wind field, and those that provide information on the temperature and humidity distribution. Satellites can also be used to provide information on surface properties, such as seaice and vegetation, but this is beyond the scope of this article. 

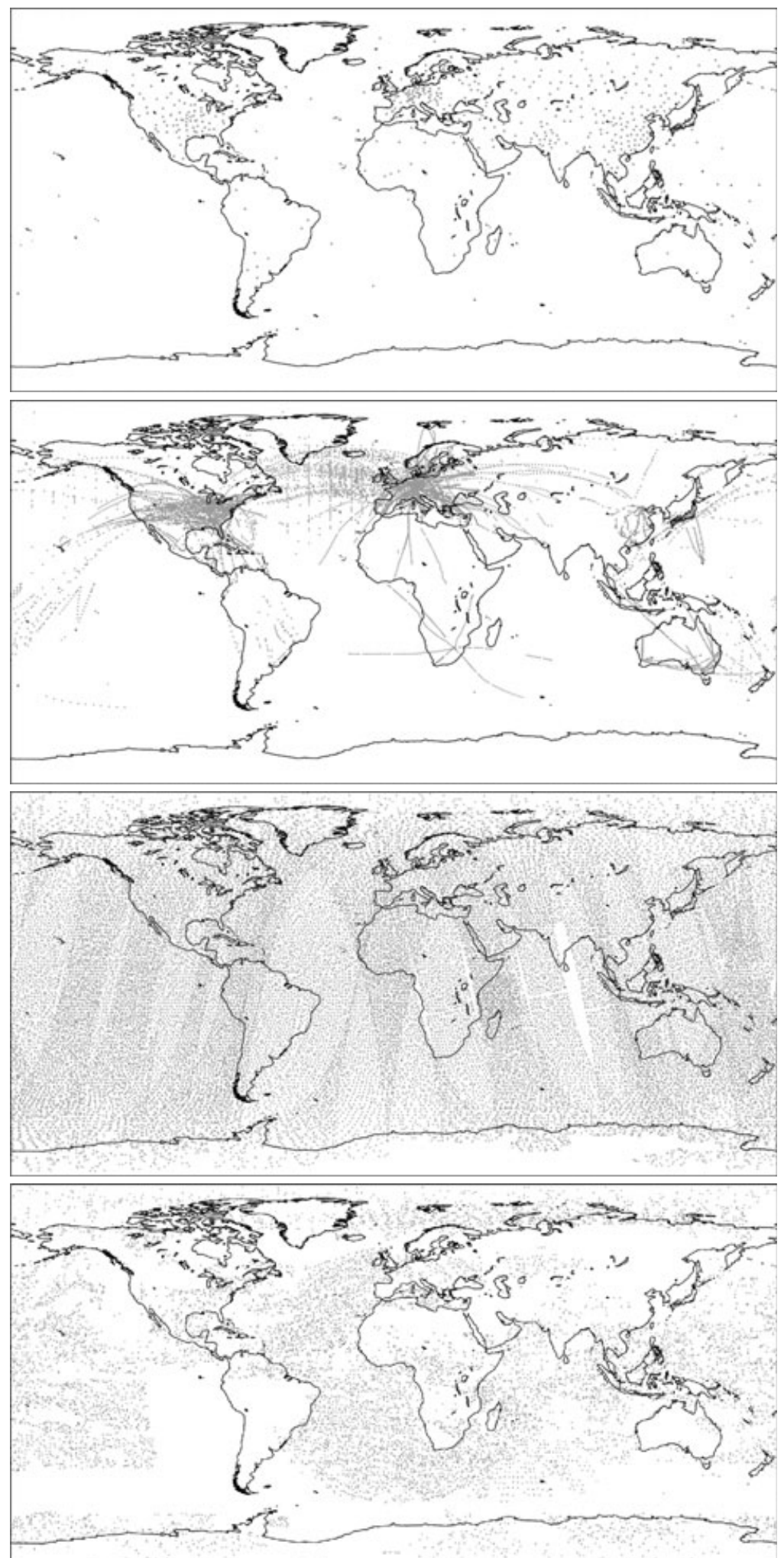

Figure 1. Coverage plots for different observations in a six-hour data assimilation cycle. Top to bottom: radiosondes, aircraft, ATOVS satellite sounding observations and satellite-derived atmospheric motion vectors.

\section{The impact of satellite data on the skill of weather forecasts}

Several studies have been performed to evaluate the relative importance to NWP of the different components of the global observing system (Kelly and Thépaut, 2007; Cardinali, 2009; Dumelow, 2009). In current, have become the most important data source for forecast quality in the short and medium range (1-10 days).

Satellite data are particularly valuable in the Southern Hemisphere, where there are few conventional observations. In the early 1990s, the forecast skill for the Southern Hemisphere was considerably worse than for the Northern Hemisphere. This gap has closed in the last two decades (Figure 2), and this is largely attributed to the impact of satellite observations filling in the data voids over the southern oceans and poorly observed land masses (Simmons and Hollingsworth, 2002; Rabier, 2005). Figure 3 illustrates the relative impact of radiosonde, aircraft and satellite observations on the accuracy of $200 \mathrm{mbar}$ wind forecasts in the ECMWF system.

Satellite sounding observations of temperature and humidity are frequently found to be the most important components of the satellite observing system in terms of their overall forecast impact. However, the strength of the global observing system lies in ensuring adequate observations of all variables which are required by the NWP model to produce a forecast. For example, the wind field is particularly important in the tropics and for constraining smallerscale features of the flow where the atmosphere is less geostrophically balanced.

Observations which are able to fill gaps in the observing system are extremely important, as NWP models may tend towards unrealistic states if there are no observations to constrain them. In these cases, reliable, accurate, well-calibrated measurements are particularly useful, and GPSRO provides such an observation source for the temperature of the upper troposphere and lower stratosphere. Advances in modelling, such as coupled atmosphere-surface models, extension into the mesosphere, and inclusion of atmospheric chemistry in NWP systems, are gradually increasing the need for a wider variety of observations.

\section{Wind observations}

Although no satellite instrument can measure the wind field directly, there are various techniques that may be used to derive wind speed and direction, such as tracking clouds or areas of water vapour in satellite image sequences (Schmetz et al., 1993; Nieman et al., 1997). The wind data produced using this approach are known as atmospheric motion vectors (AMVs). These have been assimilated operationally in NWP models since the 1980s. Over recent decades, the quality and quantity of AMV data have increased due to improvements in both the satellite imager instruments and the AMV derivation methods. Traditionally, geostationary imagery has been used owing to the frequent views it provides of the same region of the Earth's atmosphere. More recently, polar orbiter imagery (MODIS and AVHRR) has been used to provide AMVs routinely in the polar regions where successive overpasses overlap. Together, the geostationary and polar AMVs provide almost complete global coverage (Figure 1). Indeed the AMVs are the only tropospheric wind dataset to have good global coverage, particularly over the 


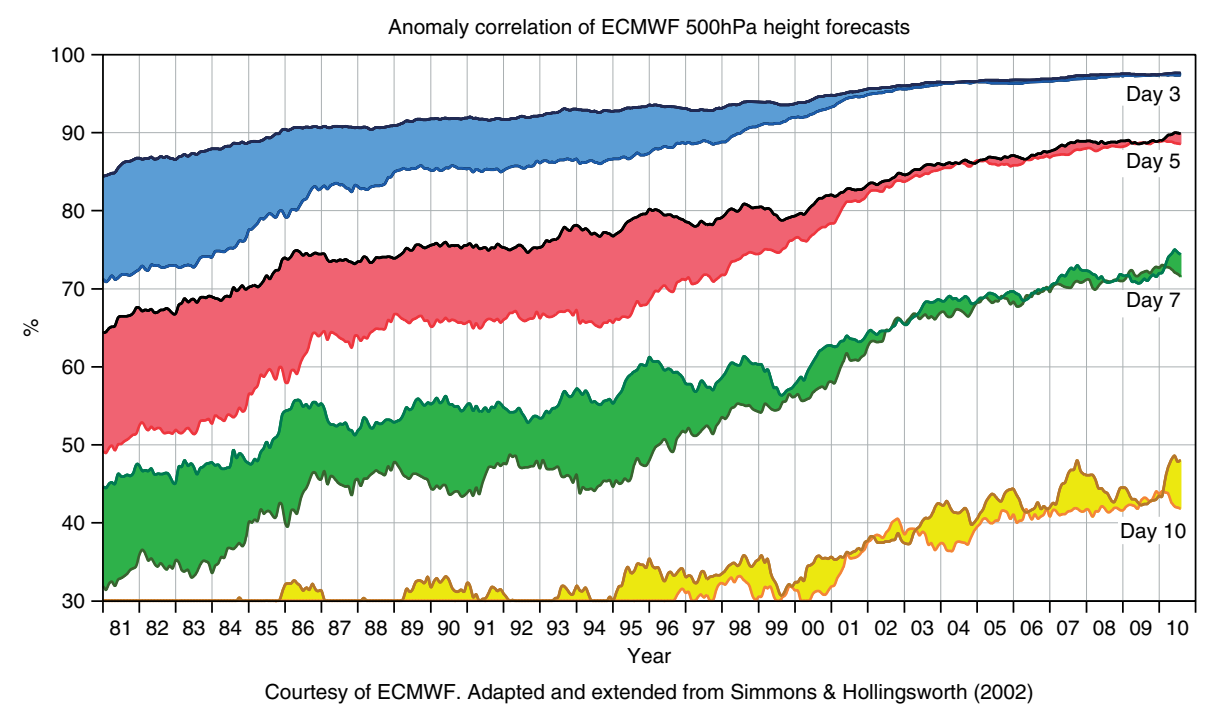

Figure 2. The evolution of forecast skill at ECMWF from 1981 to the present. The steady improvement with time can at least partly be ascribed to the improved use of satellite data and in particular the closing of the gap between the Northern and Southern Hemispheres as more and more satellite data are used in the otherwise data-sparse southern latitudes. For each day, the top of the coloured band represents the forecast skill in the Northern Hemisphere while the bottom represents the forecast skill in the Southern Hemisphere.
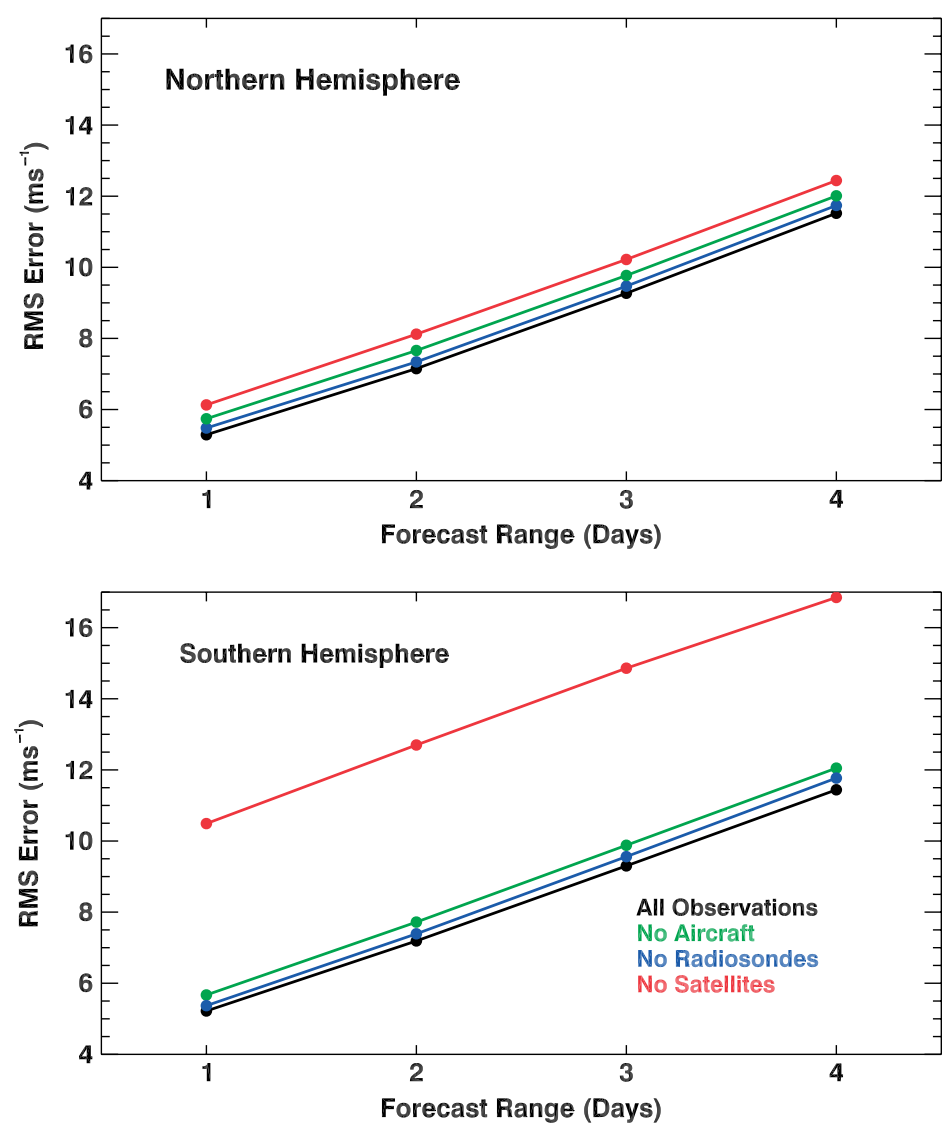

Figure 3. The impact on the root mean square 200mbar vector wind forecast error of removing radiosonde, aircraft and satellite observations from the full data assimilation system. This figure is based on results from Kelly and Thépaut (2007).

southern oceans and at high latitudes. They are, however, not without their difficulties. The biggest source of error is in their assignment to a representative level in the atmosphere. This is particularly difficult in regions with multilevel cloud, very thin cloud or a cold surface.

Satellite data can also be used to derive surface winds over the oceans, which have ried on polar-orbiting satellites are com(e.g. SeaWinds and ASCAT) and passive microwave radiometers (e.g. SSM/I and WindSat). The wind derivation in both cases is based on the effect of near-surface winds on ocean surface characteristics.
Scatterometers (Isaksen and Stoffelen, 2000; Leidner et al., 2003; Robinson, 2004) emit a microwave beam to the ocean surface at an angle. The radiation is scattered by the wind-roughened ocean surface; a small part of the emitted power will be sent back in the direction of the scatterometer antenna. This is known as backscatter. By using radiation with a wavelength of a few centimetres, the backscatter will be related to the size of small-scale ocean waves, which in turn are largely determined by the surface wind. Since these wavelets are aligned perpendicular to the wind, the backscatter response also contains information on the wind direction. By sampling the ocean surface from several directions, the wind vector can be retrieved, although with some directional ambiguity. The main challenges with scatterometer data are the removal of such ambiguities, the contamination of data by sea ice and the sensitivity to rain. Passive microwave instruments can provide information on the wind field in rain-free areas. Earlier instruments could only provide wind speed: WindSat is the first microwave radiometer capable of providing additional information on the direction (although with similar ambiguity to scatterometer instruments). This is possible because the orientation of the surface waves affects the way the emitted radiation is polarised and, unlike other microwave instruments, WindSat can measure the full polarisation state of the radiation.

The current observing network lacks detailed information on the vertical structure of the wind field. To address this, a space-borne Doppler wind LiDAR is due to be launched on the ESA ADM-Aeolus satellite within the next few years. Information on the vertical wind profile can be derived from the time delay and Doppler shift in frequency of the received signal after backscattering by aerosol particles and molecules at different heights in the atmosphere.

\section{Nadir sounding instruments}

Nadir sounding instruments measure thermally emitted radiation at infrared and microwave frequencies, and are used to provide information about the vertical structure of temperature and humidity in the column of atmosphere below the instrument.

Gases in the atmosphere emit and absorb radiation at particular frequencies depending on their molecular structure. Sounding instruments make simultaneous measurements in a number of spectral channels centred at differing wavelengths. The atmospheric transmittance will in general vary between these channels due to the absorption features of particular atmospheric gases. Any given layer of gas in the 
atmosphere will emit radiation, some of which will travel upwards towards the satellite. The emitted radiation will be attenuated by absorption in the atmospheric layers above the source layer and the amount reaching the satellite will therefore depend on the transmittance of the atmosphere above the source layer. The radiation reaching the satellite is the sum of the contributions from each layer, and the relative contribution from each layer to a particular channel is known as the weighting function.

For frequencies where the atmospheric opacity is high, most of the radiation will come from the upper layers of the atmosphere as the absorption is so strong that even a small amount of gas will mask the signal from the lower layers. In this case, the weighting function will have a peak high up in the atmosphere. For frequencies where the atmosphere is more transparent, the signal is dominated by the lower troposphere where there are a greater number of molecules emitting thermal radiation and so the weighting function will have a low peak. This concept is illustrated in Figure 4. The weighting functions for the different channels of the AMSU-A microwave radiometer are shown in Figure 5.

For a well-mixed gas, for which the vertical distribution is fairly constant and wellknown, the weighting function can be considered a function of height, and the observation can be used to infer atmospheric temperature. Carbon dioxide is used for temperature sounding by infrared instruments and oxygen by microwave sounders. For a gas such as water vapour, the weighting function peak is dependent on the amount of gas present in each layer. Water vapour has absorption bands in both the infrared and microwave parts of the spectrum, so both types of sounder are also used to provide information about the water vapour distribution in the atmospheric column. In some parts of the spectrum, known as 'window regions', there is very little absorption by the atmospheric gases, and the radiation reaching the satellite comes mostly from surface emission. At these wavelengths the radiation is determined by the surface temperature and reflectivity.

\section{Infrared sounders}

Observations of the Earth at infrared wavelengths are one of the most important components of the observation system used in NWP. The instruments observe at a number of wavelengths between 3 and $15 \mu \mathrm{m}$. In this range there are absorption features from carbon dioxide, water vapour, ozone, methane, carbon monoxide and a number of other trace gases (Figure 6). Generally, the so only channels whose main sensitivity is to carbon dioxide or water vapour are used.

Infrared wavelengths are also very sensitive to clouds and, in fact, it is this sensitivity that is the most challenging aspect of using this data type. For all currently operational NWP systems, great care is taken to minimise the influence of the cloud on the analysis when assimilating these observations. This is done either by not using the data where the effect of cloud is seen or by explicitly accounting for the cloud signal in some way. Greater use of cloud information from infrared radiances in NWP is a topic of active research.

The infrared instruments that provide the most information to NWP systems are the hyperspectral sounders: AIRS on NASA's EOS Aqua satellite (McNally et al., 2006; NASA website, http://airs.jpl.nasa.gov, accessed on 26 November 2010), and IASI on the EUMETSAT MetOp satellite (Collard and McNally, 2009; Hilton et al., 2009; CNES website, http://smsc.cnes.fr/IASI, accessed on 26 November 2010). These instruments make observations of the atmosphere at thousands of wavelengths ( 2378 for AIRS; 8461 for IASI), each sampling a slightly different range of heights in the atmosphere. By combining the information from these channels, one can infer the temperature and humidity structure in the atmosphere with a vertical resolution approaching $1 \mathrm{~km}$. Prior to these instruments, the main infrared sounder used in NWP was HIRS which has only 20 channels and has less impact on the forecast.

Data from sounding instruments on geostationary satellites are also assimilated at many NWP centres, where the main benefit is the increased temporal resolution of the measurements. In the future, we expect to see hyperspectral instruments on geostationary satellites (e.g. EUMETSAT's MTGIRS), allowing an even more detailed picture of the atmosphere to be assembled.
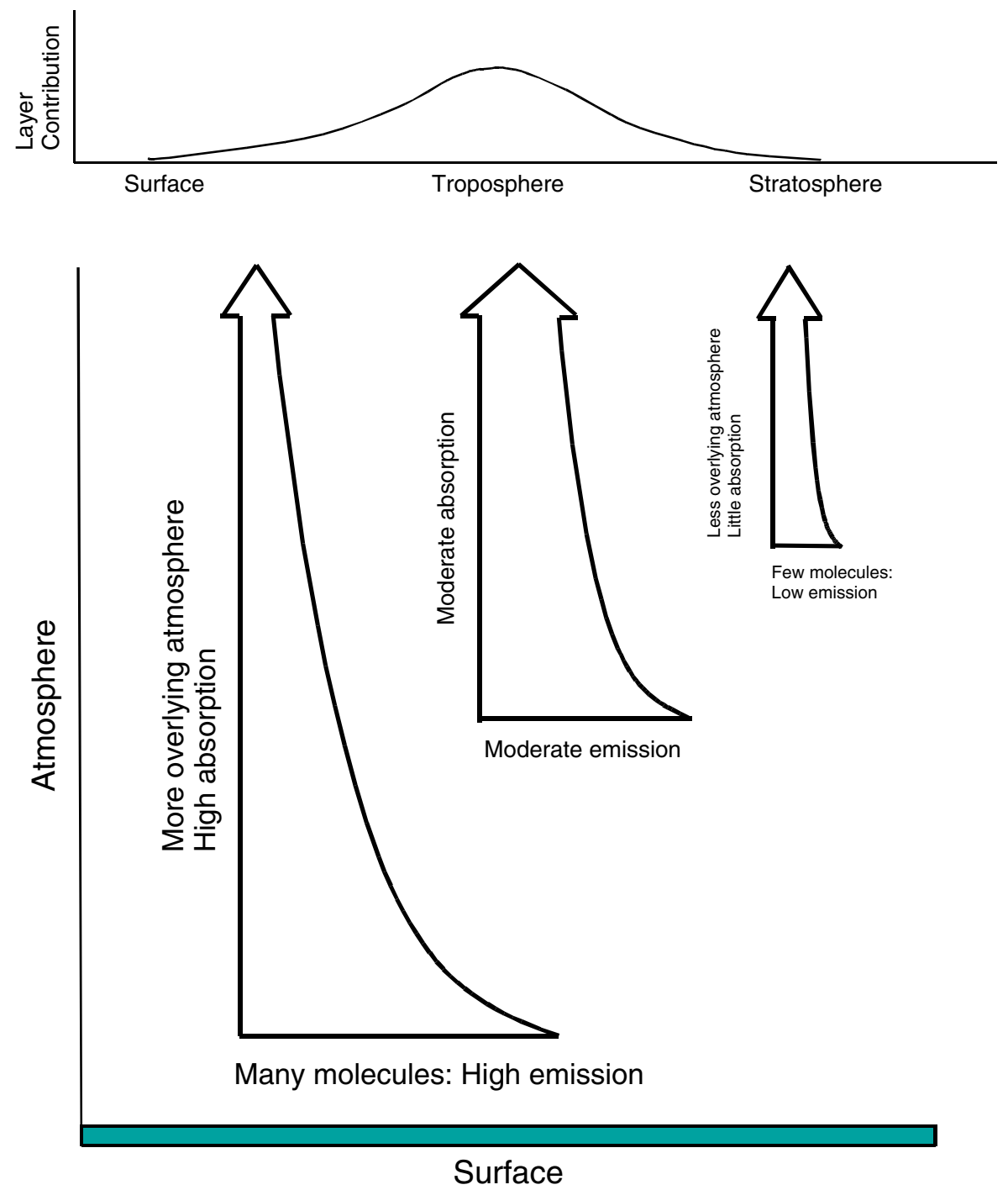

Figure 4. An illustration of how an observation made by a sounding instrument is the sum of emission terms from each layer of the atmosphere. The greatest part of the signal comes from the region where the emission from the greater number of molecules lower in the atmosphere balances the lower absorption by the atmosphere above the emitting layer. The level that contributes most to the observed signal depends on the absorption of the atmosphere at the wavelength considered. 


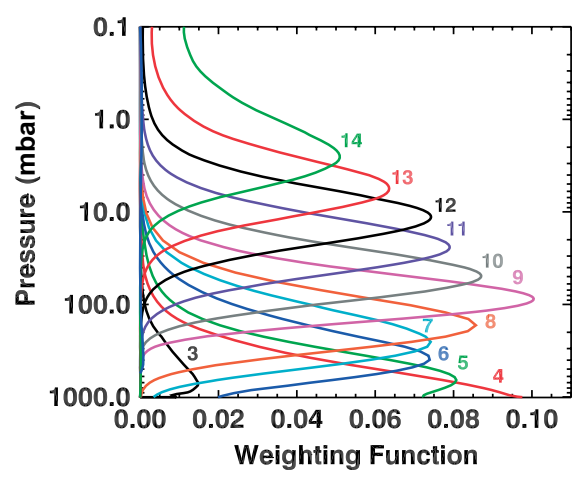

Figure 5. Weighting functions for channels 3-14 of the AMSU-A microwave radiometer. These channels have been chosen to be sensitive to the temperature in different parts of the atmosphere. The most opaque channel (Channel 14) is most sensitive to stratospheric levels. By contrast, Channel 3 is most sensitive to surface emission.

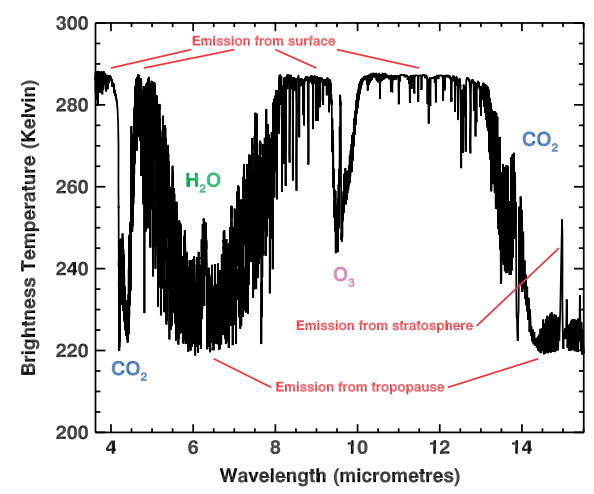

Figure 6. A simulated cloud-free IASI spectrum illustrating the main absorption features. Most of the temperature information is obtained using the strong carbon dioxide absorption band between 13 and $15 \mu \mathrm{m}$. The warmest parts of the spectrum come from emission from the relatively warm surface, while the coldest parts are from around the tropopause.

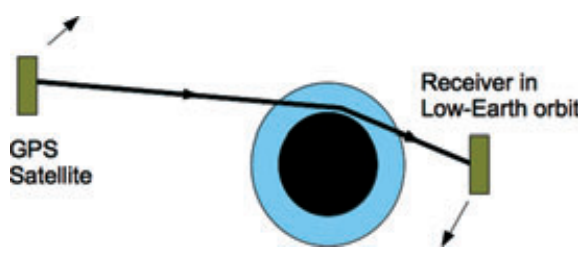

Figure 7. The geometry of a GPSRO observation. The GPS receiver is in a low-Earth orbit and receives the radio signal from a GPS satellite as it passes behind the limb of the Earth. The delay to the signal caused by the Earth's atmosphere as the GPS satellite rises or sets provides information on the atmospheric temperature and humidity profile.

\section{Microwave sounders}

The microwave sounders used for operational NWP have around 20 channels between 23 and $183 \mathrm{GHz}$ (about 1.6-13mm in wavelength). The lower frequency channels are clustered around the $50 \mathrm{GHz}$ oxygen absorption band (used for temperature sounding) and the higher frequency channels around the $183 \mathrm{GHz}$ water vapour line. The most important microwave temperature sounder is AMSU-A and its associated water vapour sounder AMSU-B (which has been replaced on recent satellites by MHS). A series of these instruments has been flown on NOAA satellites, and recently on EUMETSAT's MetOp, with complementary orbits providing near-global coverage in a six-hour NWP cycle (Figure 1). AMSU and MHS observations are often used in conjunction with infrared measurements from HIRS, and this combined microwave-infrared sounding system is known as ATOVS (English et al., 2000). The other operational microwave sounder is SSMIS, which is on the USA's operational DMSP satellites.

The main advantage of microwave sounding instruments, in comparison with infrared sounders, is the reduced sensitivity to the presence of cloud. The instruments can therefore be used to provide information on the temperature and water vapour content of the atmosphere in areas which are generally not accessible to infrared instruments. Approximately $50 \%$ of microwave sounding observations are unaffected by any cloud in the field of view and for most of the remaining observations only the lower tropospheric channels are affected by the presence of cloud liquid water to the extent that they cannot be used. The ability to use the majority of the data in cloudy areas is very important for NWP, as the most meteorologically active regions tend to be cloudy. AMSU-A/B and MHS together give similar impact to the hyperspectral infrared sounders - their ability to provide an even coverage in cloudaffected regions compensates for their lower horizontal and vertical resolution.

At certain frequencies in the microwave spectrum, the radiation comes not only from thermal emission but is affected by scattering from rain droplets or ice particles. The microwave window channels are sensitive to the presence of precipitation, and higher frequency channels, such as the $183 \mathrm{GHz}$ water vapour channels, are sensitive to scattering by ice. They can therefore provide information on active weather systems, although feeding this information into the NWP model via the data assimilation system is difficult and is still an area of active research.

A related family of instruments, the microwave imagers, which have channels in the microwave windows at 19,22 and $37 \mathrm{GHz}$, is used to provide information on total column moisture. These observations are also starting to be used to provide information on precipitation. The main sensors in this family are SSM/I on the older generation of DMSP satellites and similar channels on SSMIS. AMSR-E on board EOS Aqua can also be used to derive information on precipitation.

\section{GPS radio-occultation}

A relatively recent addition to the suite of instruments that contribute to NWP is the GPS Radio Occultation (RO) constellation (Kursinski et al., 1997; Healy and Thépaut, 2006). Receiving instruments on low-Earth orbiting satellites take advantage of the radio signals that are emitted from the existing GPS constellation, orbiting much higher at around $20000 \mathrm{~km}$. The signals contain precise timing information that is normally used to infer the position of a receiver on the Earth, but when the signal has passed through the Earth's atmosphere the timing information can be used by the RO instrument to determine how the atmosphere has bent and delayed the signal. This bending of the radio signal is related to the refractive index profile of the atmosphere and so to pressure, temperature and humidity.

The geometry of a GPSRO observation is illustrated in Figure 7. The measurement consists of a series of observations for different tangent heights as, seen from the point of view of the receiving satellite, the GPS satellite rises or sets behind the Earth. These measurements have the advantage of very high vertical resolution (a few hundred metres), are insensitive to the effect of clouds and have very accurate calibration. They are also much cheaper than most other meteorological instruments. Although the number of observations is limited by the number of opportunities to make the measurements, GPSRO is an important observation type, in particular because it is very sensitive to the atmospheric state around the tropopause which is otherwise not well observed. The observations have also proved invaluable in providing useful constraints on the interpretation of observations from other satellites, and in investigating errors in the NWP model and in other observing systems.

\section{Summary}

Satellite observations combine to form the most important source of observations in NWP, and provide information on atmospheric and surface temperature, water vapour and wind fields. This article has described the main types of satellite observations used in numerical weather prediction, but it is not an exhaustive account. The growing importance of air quality forecasting, and links to climate studies, means that information on aerosol and chemical species is also of increasing interest. Satellite observations, with their global coverage, are ideally suited to providing this type of information. The MACC project (http://www. gmes-atmosphere.eu/) is one example of active research in this area.

Innovative improvements in the use of existing data are constantly sought, and 
Acronyms and Abbreviations

\begin{tabular}{ll}
\hline ADM & Atmospheric Dynamics Mission \\
AIRS & Atmospheric Infrared Sounder \\
AMV & Atmospheric Motion Vector \\
AMSR-E & The Advanced Microwave Scanning Radiometer - EOS \\
AMSU & Advanced Microwave Sounding Unit \\
ASCAT & Advanced Scatterometer (EUMETSAT) \\
ATOVS & Advanced TIROS Operational Vertical Sounder (comprises AMSU-A, AMSU-B or \\
& MHS and HIRS) \\
AVHRR & Advanced Very High Resolution Radiometer \\
DMSP & Defense Meteorological Satellite Program \\
EOS & Earth Observing System (a NASA satellites series) \\
ESA & European Space Agency \\
ECMWF & European Centre for Medium-Range Weather Forecasts \\
EUMETSAT & European Organisation for the Exploitation of Meteorological Satellites \\
GPS & Global Positioning System \\
GPSRO & Global Positioning System Radio Occultation \\
HIRS & High-resolution Infrared Radiation Sounder \\
IASI & Infrared Atmospheric Sounding Interferometer \\
IRS & Infrared Sounder \\
LiDAR & Light Detection And Ranging \\
MACC & Monitoring Atmospheric Composition and Climate \\
MHS & Microwave Humidity Sounder \\
MetOp & EUMETSAT Meteorological Operational satellite \\
MODIS & MODerate resolution Imaging Spectroradiometer \\
MTG & Meteosat Third Generation \\
NASA & National Aeronautics and Space Administration \\
NOAA & National Oceanic and Atmospheric Administration \\
NWP & Numerical Weather Prediction \\
RO & Radio occultation \\
SSM/I & Special Sensor Microwave Imager \\
SSMIS & Special Sensor Microwave Imager Sounder \\
TIROS & Television InfraRed Observation Satellite \\
& \\
&
\end{tabular}

many centres are beginning to make use of information on cloud properties and precipitation from satellite observations to improve weather forecasts in meteorologically active areas. Every year new instruments provide more data, improving the coverage and filling gaps in the global observing system. The hugely important role of satellite data in NWP is therefore set to continue to grow over the coming decades.

\section{Acknowledgements}

The authors would like to thank John Eyre, Sean Healy, and James Cotton for useful discussions. We would also like to thank Adrian Simmons, Graeme Kelly and Sean Healy for helping with figures. The quality of this article was also improved by the input from an anonymous reviewer.

\section{References}

Cardinali C. 2009. Monitoring the observation impact on the short-range forecast. Q. J. R. Meteorol. Soc. 135: 239-250.

Collard AD, McNally AP. 2009. The assimilation of Infrared Atmospheric Sounding Interferometer radiances at ECMWF. Q. J. R. Meteorol. Soc., 135: 1044-1058.
Daley R. 1991. Atmospheric data analysis. Cambridge University Press: Cambridge, UK. Dumelow R. 2009. 'Global data denial experiments using 4D-Var.' Met Office Meteorology Research and Development Technical Report 532. http://research. metoffice.gov.uk/research/nwp/ publications/papers/technical_reports/ reports/532.pdf [accessed 26 November 2010]

ECMWF. 2010. ECMWF Data Assimilation Course notes http://www.ecmwf.int/ newsevents/training/lecture_notes/LN DA.html [accessed 26 November 2010]

English SJ, Renshaw RJ, Dibben PC, Smith AJ, Rayer PJ, Poulsen C, Saunders FW, Eyre JR. 2000: A comparison of the impact of TOVS and ATOVS satellite sounding data on the accuracy of numeri126: 2911-2931.

Healy S, Thépaut J-N. 2006. Assimilation experiments with CHAMP GPS radio occultation measurements. Q. J. R. Meteorol. Soc. 132: 605-623.

Hilton F, Atkinson NC, English SJ, Eyre JR. 2009. Assimilation of IASI at the Met Office and assessment of its impact through observing system experiments. Q. J. R. Meteorol. Soc. 135: 495-505.

Isaksen L, Stoffelen A. 2000. ERS scatterometer wind data impact on ECMWF's cal weather forecasts. Q. J. R. Meteorol. Soc. tropical cyclone forecasts. IEEE $T$ Geosci. Remote, 38(4): 1885-1892.

Kalnay E. 2003. Atmospheric Modeling, Data Assimilation and Predictability. Cambridge University Press:

Cambridge, UK

Kelly G, Thépaut J-N. 2007. Evaluation of the impact of the space component of the Global Observing System through Observing System Experiments. ECMWF Newsletter No.112.

Kidd C. 2010. From Observations to Forecasts - Part 3. Key principles and recent developments in satellite observations. Weather 65: 3-9.

Kursinski E, Hajj G, Schofield J, Linfield R, Hardy K. 1997. Observing earth's atmo sphere with radio occultation measurements using the Global Positioning System. J. Geophys. Res. 102: 23, 429-23, 465.

Leidner SM, Isaksen L, Hoffman RN. 2003. Impact of NSCAT winds on tropical cyclones in the ECMWF 4DVAR assimilation system, Mon. Weather Rev. 131: 3-26.

McNally AP, Watts PD, Smith JA

Engelen R, Kelly GA, Thépaut J-N, Matricardi M. 2006. The assimilation of AIRS radiance data at ECMWF. Q. J. R. Meteorol. Soc. 132: 935-957.

Nieman SJ, Menzel WP, Hayden CM, Gray D, Wanzong ST, Velden CS, Daniels J.1997. Fully automated cloud drift winds in NESDIS operations. B. Am. Meteorol. Soc. 78:1121-1133.

Rabier F. 2005. Overview of global data assimilation developments in numerical weather-prediction centres. Q. J. $R$. Meteorol. Soc. 131: 3215-3233.

Robinson IS. 2004. Measuring the Oceans from Space (Chapter 9). Springer.: New York, NY, USA

Rodgers CD. 2000. Inverse Methods for Atmospheric Sounding Theory and practice. World Scientific Publishing Co. Singapore.

Schmetz J, Holmlund K, Hoffman J, Stauss B, Mason B, Gaertner V, Koch A, Van der Berg L.1993. Operational cloud-motion winds from Meteosat infrared images. J. Appl. Meteorol. 32: 1206-1225.

Simmons AJ, Hollingsworth A. 2002. Some aspects of the improvement in skill of numerical weather prediction. Q. J. $R$. Meteorol. Soc. 128: 647-677.

Correspondence to: Andrew Collard World Weather Building \#207,

5200 Auth Road,

Camp Springs MD 20746, USA

andrew.collard@noaa.gov

(c) Royal Meteorological Society and Crown Copyright, 2011

\section{DOI: 10.1002/wea.736}

†The contributions of F. Hilton, M. Forsythe and B. Candy were written in the course of their employment at the Met Office, UK and are published with the permission of the Controller of HMSO and the Queen's Printer for Scotland 